\title{
Users' Attention Behaviors and Features in Internet Forum
}

\author{
Yong-Zhong Sha, Li Lu \\ School of Management, Lan₹̧ou University (China) \\ shayzh@,lzu.edu.cn, lul13@,liu.edu.cn
}

Received: April 2015

Accepted: October 2015

\section{Abstract:}

Purpose: Attention resource is scarce. Organizing community activities in online forums faces the challenge of attracting users' limited attention. Understanding how users of online forums allocate, maintain, and change their attentional focus and what features of online forms influence their attention behaviors is critical for effective information design. This paper seeks understanding of users' attention behaviors and features when they participate in discussions in online forums.

Design/methodology/approach: A conceptual model was established to explore the indicator system of attention's measurement. The related attention data were collected from Alexa Access Statistics Tool and Katie community. Then this paper computed the correlation coefficient and regression relationship between the indicators of visual attention and cognitive attention. Thereafter this paper analyzed and discussed users' attention behaviors and features in Internet forum.

Findings: Relevant bivariate correlation analysis and regression analysis discovers that Internet forum's attention is mainly as visual attention in users' early involvement. Attention resources can be transformed. In a deep participation, users' cognitive attention is more significant. Meanwhile cognitive attention behaviors' further development will lead to the phenomenon that cognitive attention input is prone to increase faster in the early duration. That means indepth discussion and interaction are more likely to appear in the early stages of participation. 
Research limitations/implications: There are some limitations about this study. The indicators are not comprehensive enough because factors affecting the distribution of attention resources in Internet forums are complex. We didn't distinguish different types of Internet forums when we collected the relevant data. Future research will focus more on how to obtain comprehensive attention data.

Originality/value: $\mathrm{T}$ his paper shows a new perspective that we can find users' attention behaviors and features using the attention data from its mapping object, which can help operators of portals and Internet communities to attract users' limited attention.

Keywords: attention, internet forum, attention data, features

\section{Introduction}

Our society has entered an era of attention economy (Davenport \& Beck, 2001). The most pressing issue is that people's attention is not sufficient to satisfy the needs of business and society. As government and business services are migrated to online environment through highly interactive websites and social media, attracting attention of users is critical for engaging the public, promoting business value, enhancing social identity, and inserting influence through information dissemination. However, people have only limited capacity to attend and process information. Given the wealth of competing stimuli that demand human processing, attention becomes a scarce resource.

For an online community to thrive, it must first be able to attract users' attention. One way to achieve this is by designing information structures and presentation purposefully for attention attraction. Such design can be informed by understanding how users allocate attention and decide what to focus on from moment to moment. Such insight can guide the development of more targeted service contents and visual appearance so that it stands out in the competition of attention in the environments where users are overloaded by a large number information sources and stimuli. In this paper, we are especially interested in understanding user attention behavior and exploring attention distribution features in online forums that support local community engagement.

Attention is a highly complex phenomenon ( $W u, 2011)$. As an important part of cognitive processes, attention has broad effects, complex features and various forms. Two mechanisms affect attention: cognitive and perceptual. The perceptual considers the subject's ability to perceive or ignore stimuli, while cognitive refers to the actual processing of the stimuli for certain tasks. Visual attention is thought to operate as a two-stage process (Koch \& Ullman, 1987). In the first stage, attention is distributed uniformly over the external visual scene and 
processing of information is performed in parallel. Directing attentions at this stage does not need much conscious thoughts, and therefore known as "pre-attentive" mode. In the second stage, attention is concentrated to a specific area of the visual scene (i.e., it is focused), and processing is performed in a serial fashion. This stage requires conscious processing (therefore "attentive").

Theories of human attention have significant implications on the information design of online services. Wolfe, Friedmanhill and Bilsky (1994) showed that proper visual encoding of information using certain combination of basic visual features (color, size, etc.) can guide attention to targets defined by conjunctions of those features. Baluja and Pomerleau (1997) demonstrated that different regions of the retina are specialized in attending different task-specific stimuli (such as visual monitoring and control of a robot vehicle), and they captured such knowledge by a saliency map. The level of attention on an information object affects memory and learning (Potter \& Balthazard, 2004). Courbet, Fourquet-Courbet, Kazan and Intartaglia (2014) showed that, when pop-up ads for a new brand are viewed at low-level attention, users tend to forget seeing them very quickly. Hong, Thong and Tam (2004) studied how animation attracts online users' attention and discussed the effects of flash on information search performance and perceptions. Huang and Luo (2007) studied the relationship between attention shortage and negative stimuli. Schneider (2002) described the Knowledge-AttentionGap when facing information overload in knowledge management. Netto, Assunçao and Bianchi (2013) attempted to leverage attention scarcity, explore signals that influence the manner users make requests and improve user experience when interacting with cloud services.

Research on attention commonly takes one of the two forms. Some explore the relationship between attention and other objects, using the attention as an independent or a dependent variable. Others discover and describe the characteristics of attention itself. Either way, researchers must be able to measure attention and its changes. Unfortunately, intention is a mental phenomenon that is not directly observable. Researchers have been using instruments to measure eye movement or brain's visual cortex activities as evidences of attention focus, selection, and change. Alternatively, this paper follows a different approach that uses observed user behavior as proxy measures of visual and cognitive attention. This is based on the assumption that there are intrinsic connections between the internal operation of attention and the external behavior when human interact with information. In order to establish such connections, we adopt a conceptual model that explicitly maps attention's attributes to behavior measures (see section 2.1.). We apply this method to the analysis of behavioral data collected from an online forum, which serves as a virtual "public sphere" (Dahlberg, 2001) for communities to meet. By collecting and analyzing online forum data, we are able to characterize users' visual attention behaviors and cognitive attention behaviors. The purpose is to discover distribution characteristics of users' attention resources, support the Internet forum management, and inform the design of network information service. 


\section{Methodology}

\subsection{Conceptual Model}

In the context of this paper, attention is defined as focused mental engagement on a particular item of information (Davenport \& Beck, 2001), and can be measured as time spent interacting with someone or something (Simon,1971). We adopt a conceptual model of Attention's Mapping Objects (see Figure 1) which describes how a system of attention-related concepts inter-connect. This model recognizes that attention has multiple forms (visual, auditory, cognitive, etc) (Zhang, 2002).

An online forum is a web application for publishing user-generated content in the form of discussion (Morzy, 2009). When users interact with each other in the forum, they may author text contents to actively engage with the ongoing conversations, or they may read or view other peoples' expressions passively (Kortelainena \& Katvalab, 2012). Both forms of participation will leave digital traces that record people's attention behavior. When users interact with an online forum, they may exhibit a variety of behaviors. Some of these behaviors are related to visual attention, and another subset of user behaviors reflects cognitive attention. As people leaves their digital footprints while participating an online forum, they make their attention data (such as time spent or citations) available as proxy measure of their attention.

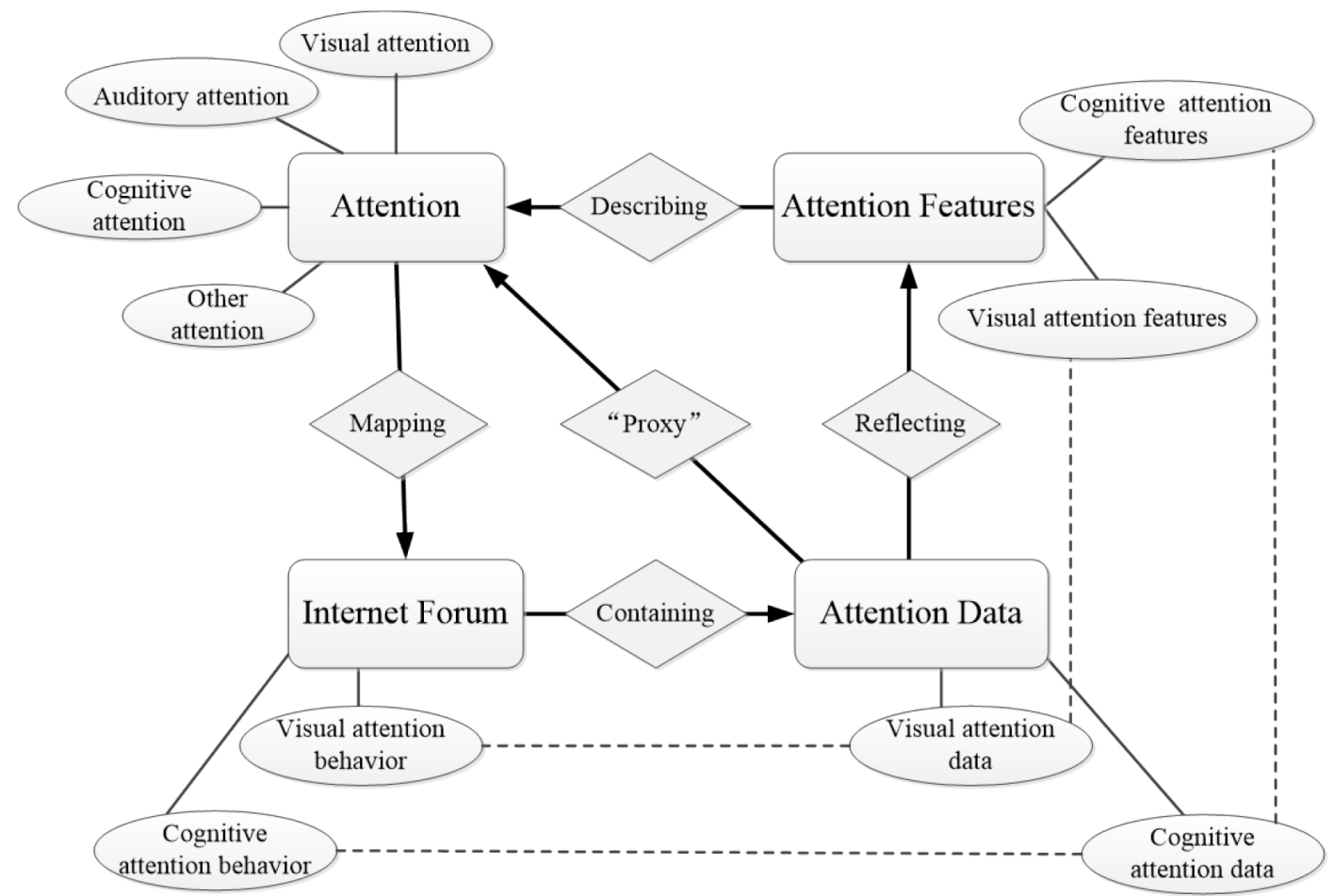

Figure 1. The conceptual model of this research 


\subsection{Indicator System}

Attention data consist of elements that reveal somebody's attention on a message (Kortelainena \& Katvalab, 2012). Internet forum users' attention behaviors have some kind of "digital footprint". Thus indicator system of this paper consists of two parts: visual attention behavior and cognitive attention behavior.

Visual attention behavior is "what users look" and "how they look". So the indicators of visual attention are presented like this:

- Bounce rate: Bounce rate represents the percentage of visitors who enter the site and then leave ("bounce") rather than continuing on to view other pages within the same site. (Wikipedia, 2015). Bounce rate can reflect users' visual attention behavior. If an Internet forum has higher bounce rate, then that means this forum is unattractive and cannot attract users' visual attention well.

- Average page views: Average page views are the total number of page views divided by the total number of visits. If an Internet forum has a higher average page views, then the forum has higher viscosity. The more webpage users browse, the more attention resources they will pay.

- Page load time: Optimizing the website needs showing contents as quickly as possible. Page load time has an effect on the users' visual attention behavior.

When forum has "loyal users", cognitive attention is more significant to reflect users' attention in a deep participation. So the indicators of cognitive attention are presented like this:

- Clicks: Total clicks of the post.

- Replies: Total replies of the post (or the number of comments).

- Response rate: Replies of the post divided by the total clicks of post.

- Reply time: The difference value that time of first reply subtracts time of creating the post.

- Duration: The difference value that time of last reply subtracts time of creating the post.

- Interaction: The maximum of round number in the interactive replies.

It should be pointed out that clicks can be indicators of either visual attention or cognitive attention, which shows the connection between them. 


\subsection{Analytical Procedures}

The method of our analysis consists of the following steps:

- Collect attention data. The attention data has two parts. Visual attention data comes from the third evaluation activity of world's most influential top 100 Chinese Internet forums. We used the Alexa Access Statistics Tool to get the bounce rate, average page views and page load time of the top 60 forums (Table 1). Cognitive attention data comes from Katie community. Using Meta Seeker tool, we searched the data with the keyword "MH370" from March 8, 2014 to April 18, 2014 and got 1320 relevant posts.

- Clean data. Some of the data collected from search may not reflect attention behavior, and therefore can be removed. This step generates 1212 relevant posts from 58 online forums.

- Calculate basic statistics for each indicator. The results characterize the general distribution attention features in terms of their central tendency (mean), spread (standard deviation) and so on.

- Calculate correlation coefficient. With the two-sided test and Pearson correlation coefficient, we used SPSS software to compute the correlation coefficients between different indicators. The results of bivariate correlations were used for analyzing the relationships among variables and for discovering interesting patterns of distribution in the feature space of attention.

- Assess relationships among attention indicator variables. In order to find functional relationship between the variables with significant associations, we used the SPSS software to perform linear regression and curve estimation. The results are interpreted to identify functional relationship between clicks, replies, response rate, reply time, duration and interaction, which can be used to analyze the relationship between visual attention and cognitive attention.

- Plot fitted line. After obtaining the regression coefficient and results of curve estimation, we plotted fitted line to show some features of attention by graph.

\begin{tabular}{|c|l|r|r|r|r|}
\hline Ranking & \multicolumn{1}{|c|}{ Forum name } & $\begin{array}{c}\text { National } \\
\text { ranking }\end{array}$ & Bounce rate & $\begin{array}{c}\text { Average page } \\
\text { view }\end{array}$ & $\begin{array}{c}\text { Page load time } \\
\text { (second) }\end{array}$ \\
\hline 1 & Tianya Community & 29 & $34.60 \%$ & 7.22 & 1.467 \\
\hline 2 & Phoenix Net BBS & 13 & $12.50 \%$ & 5.96 & 1.071 \\
\hline 3 & Baidu Post Bar & 1 & $15.60 \%$ & 10.11 & 1.383 \\
\hline 4 & Mop Community & 213 & $48.20 \%$ & 4.55 & 1.677 \\
\hline 5 & Sohu BBS & 8 & $27.70 \%$ & 3.93 & 1.402 \\
\hline 6 & Netease BBS & 10 & $17.80 \%$ & 7.61 & 1.32 \\
\hline 7 & Katie Community & 235 & $5.10 \%$ & 4.6 & 3.931 \\
\hline 8 & Sina BBS & 4 & $23.80 \%$ & 6 & 1.377 \\
\hline
\end{tabular}




\begin{tabular}{|c|c|c|c|c|c|}
\hline Ranking & Forum name & $\begin{array}{l}\text { National } \\
\text { ranking }\end{array}$ & Bounce rate & $\begin{array}{l}\text { Average page } \\
\text { view }\end{array}$ & $\begin{array}{l}\text { Page load time } \\
\text { (second) }\end{array}$ \\
\hline 9 & China net BBS & 19 & $21.80 \%$ & 16.9 & 2.109 \\
\hline 10 & People's Daily online BBS & 17 & $9.90 \%$ & 6.66 & 4.063 \\
\hline 11 & HuaSheng BBS & 195 & $12.10 \%$ & 4.02 & 3.598 \\
\hline 12 & China bbs & 807 & $24.30 \%$ & 12 & 2.269 \\
\hline 13 & Iron \& Blood & 303 & $41.70 \%$ & 4.19 & 2.067 \\
\hline 14 & XICI & 294 & $43.70 \%$ & 3.1 & 1.668 \\
\hline 15 & XiLu BBS & 613 & $45.20 \%$ & 3.83 & 3.678 \\
\hline 16 & Red net BBS & 84 & $14.30 \%$ & 10.53 & 1.555 \\
\hline 17 & Interaction China - peace BBS & 25 & $9.30 \%$ & 4.68 & 3.976 \\
\hline 18 & The 19th Floor BBS & 658 & $31.20 \%$ & 8.8 & 0.828 \\
\hline 19 & Tencent BBS & 2 & $26.50 \%$ & 6.13 & 1.255 \\
\hline 20 & Taobao BBS & 3 & $23.30 \%$ & 8.96 & 1.25 \\
\hline 21 & China Ren Community & 972 & $44.60 \%$ & 2.18 & 0.344 \\
\hline 22 & Xinhua net BBS & 16 & $12.40 \%$ & 5.96 & 3.77 \\
\hline 23 & GT Forum & 40 & $8.40 \%$ & 3.83 & 3.832 \\
\hline 24 & Sogou Desktop BBS & 20 & $41.40 \%$ & 3.02 & 0.975 \\
\hline 25 & AoYi BBS & 1620 & $61.80 \%$ & 2.45 & 1.388 \\
\hline 26 & Tom BBS & 460 & $39.70 \%$ & 3.16 & 0.614 \\
\hline 27 & Yahoo Word-of-mouth BBS & 864 & $46.30 \%$ & 4.67 & 2.444 \\
\hline 28 & MSN Financial Community & 17 & $9.90 \%$ & 6.66 & 4.063 \\
\hline 29 & Financial Stocks BBS & 58 & $3.20 \%$ & 4.25 & 3.222 \\
\hline 30 & Bubble Club & 166 & $4.10 \%$ & 4.34 & 3.907 \\
\hline 31 & $21 \mathrm{CN}$ Community & 308 & $44.00 \%$ & 5.29 & 1.701 \\
\hline 32 & China News Community & 97 & $48.80 \%$ & 4.98 & 1.45 \\
\hline 33 & CCTV BBS & 54 & $32.00 \%$ & 4.11 & 2.424 \\
\hline 34 & China National Radio website BBS & 385 & $48.90 \%$ & 3.08 & 1.892 \\
\hline 35 & CRI Online BBS & - & - & - & - \\
\hline 36 & Beijing BBS & 127 & $10.30 \%$ & 3.65 & 2.748 \\
\hline 37 & Smth BBS & 459 & $26.70 \%$ & 4.81 & 1.006 \\
\hline 38 & 55BBS & 152 & $3.00 \%$ & 3.49 & 3.797 \\
\hline 39 & Green Qingdao Community & 119 & $11.70 \%$ & 9.35 & 1.401 \\
\hline 40 & KDS Community & 478 & $32.40 \%$ & 14.1 & 1.285 \\
\hline 41 & ChinaZ BBS & 26 & $25.10 \%$ & 5.42 & 1.259 \\
\hline 42 & DaYang BBS & 1215 & $47.80 \%$ & 4.45 & 1.235 \\
\hline 43 & Sichuan Tianfu online BBS & 7914 & $43.60 \%$ & 4.5 & 2.096 \\
\hline 44 & Henan DaHe BBS & 840 & $42.70 \%$ & 4.05 & 1.681 \\
\hline 45 & Shandong DaZhong Community & 349 & $49.10 \%$ & 4.59 & 1.9 \\
\hline 46 & Sichuan Spicy Community & 3070 & $26.40 \%$ & 17 & 2.48 \\
\hline 47 & Hoop China Sports BBS & 86 & $10.30 \%$ & 7.08 & 3.091 \\
\hline 48 & IT168 Products BBS & 44 & $5.50 \%$ & 4.26 & 4.051 \\
\hline 49 & The Southern BBS & 618 & $38.30 \%$ & 3.99 & 2.317 \\
\hline 50 & Hexun Finance BBS & 103 & $56.00 \%$ & 2.74 & 2.136 \\
\hline 51 & China's silicon valley Online BBS & 28 & $16.90 \%$ & 5.22 & 3.582 \\
\hline 52 & Pconline BBS & 24 & $19.10 \%$ & 4.79 & 3.738 \\
\hline 53 & The Laggard Webmaster BBS & - & - & - & - \\
\hline 54 & 17173 Game Community & 222 & $47.00 \%$ & 4.03 & 1.513 \\
\hline 55 & Soufun Owner BBS & 126 & $21.30 \%$ & 13.27 & 1.724 \\
\hline 56 & XDnice BBS & 1868 & $28.60 \%$ & 16.1 & 1.758 \\
\hline 57 & UC Official Technology BBS & 1136 & $41.00 \%$ & 2.62 & 1.241 \\
\hline 58 & Everybody BBS & 2595 & $40.20 \%$ & 5.2 & 3.223 \\
\hline 59 & ShangDu BBS & 720 & $36.70 \%$ & 5.36 & 1.991 \\
\hline 60 & QiDian Chinese Community & 191 & $29.40 \%$ & 9.5 & 2.901 \\
\hline
\end{tabular}

Table 1. Alexa Statistical data of sample forums 


\section{Results}

\subsection{Visual Attention Features Analysis}

The type of website affects users' visual attention behaviors. Table 2 shows that the mean of bounce rate of Internet forums is $28.3310 \%$, and the average page views in one day are 6.1609 pages. Generally the judgment of bounce rate is within $50 \%$ and lower is better, and the average page views can reflect the website's viscosity. Statistical results indicate that the information contents and users' experience provided by Internet forums can better catch users' visual attention.

\begin{tabular}{|l|r|r|r|r|}
\hline \multicolumn{1}{|c|}{ Variable } & \multicolumn{1}{c|}{ Mean } & Standard deviation & \multicolumn{1}{c|}{ Min } & \multicolumn{1}{c|}{ Max } \\
\hline Bounce rate & $28.3310 \%$ & 15.68250 & $3.00 \%$ & $61.80 \%$ \\
\hline Average page views per day & 6.1609 & 3.60076 & 2.18 & 17.00 \\
\hline Page load time & 2.20903 & 1.064778 & 0.344 & 4.063 \\
\hline
\end{tabular}

Table 2. Descriptive statistics of visual attention data

Web page load time also affects the user's visual attention behaviors. Longer page load time is generally considered to lead to the transfer of user's visual attention more easily and increase website's bounce rate. In Table 3, the Pearson correlation coefficient between forum bounce rate and page load time is -0.548 , and significance level is $p<0.001$. The result indicates that there is a significant negative correlation between Internet forum's bounce rate and average page load time. That is to say the longer average page load time is, the higher forum's bounce rate will be. That phenomenon may be influenced by the Internet forum information particularity. On one hand comparing with waiting time, the information contents of Internet forums play a more important role on attracting the attention of users. Meanwhile, forum information has the feature of "fragmentation". Users also tend to make attention resources "fragmentation" in processing information selection and discovery. That makes it difficult to go deep into contents and results in higher bounce rate. On the other hand, picture loading or complex forum structure will increase page load time. But the eyecatching pictures and explicit navigation can often attract more users' visual attention, making them discover information needed rapidly and accurately. It will also reduce bounce rate. 


\begin{tabular}{|c|c|c|c|}
\hline & Variable & 1 & 2 \\
\hline 1 & Bounce rate & - & - \\
\hline 2 & Page load time & $-0.548 * * *$ & \\
\hline
\end{tabular}

Note: $N=58$. The lower triangular matrix is correlation coefficients, $* p<0.05, * * p<0.01, * * * p<0.001$.

Table 3. Correlation analysis between forum's bounce rate and page load time

\subsection{Cognitive Attention Features Analysis}

Cognitive attention behaviors last longer after users go deep into forum discussion. As can be seen from the descriptive statistics of indicator variables of cognitive attention, replies, response rate and interaction all show the style of normal distribution in the duration of topic discussion. That reflects the normal distribution characteristics of overall cognitive attention inputted by Internet forum users to some extent (Table 4).

Cognitive attention in Internet forums is mapped into the different levels of behaviors, including click to browse, reply and interactive discussion. Table 5 shows that there are several sets of significant correlation relationships between different indicator variables of cognitive attention. With a significance level of $p<0.001$, the Pearson correlation coefficient between forum replies and clicks is 0.926. The result indicates that there is a significant positive correlation relationship between forum replies and clicks. That means the more clicks on main posts are, and then the more replies and comments are. The Pearson correlation coefficient between replies and interactions is 0.530 , indicating that between forum replies and interactions, there also exists a significant positive correlation relationship, namely more replies, deeper interactions. In summary, putting more cognitive attention into the fore period of participation superficially makes it easier to lead the cognitive attention into deep levels.

\begin{tabular}{|l|r|r|r|r|}
\hline & Mean & Standard deviation & Min & 1 \\
\hline Replies & 34.15 & 101.586 & 33 & 2320 \\
\hline Clicks & 7930.10 & 25294.695 & 440352 \\
\hline Response rate & 0.006595192964 & 0.0035307767693 & 0.0007745933 & 0.0336269030 \\
\hline Interaction & 2.57 & 2.932 & 1 & 32 \\
\hline Reply time(minute) & 16.89 & 175.264 & 0 & 5682 \\
\hline Duration(minute) & 3504.59 & 8761.173 & 1 & 70236 \\
\hline
\end{tabular}

Note: $N=1212$.

Table 4. Descriptive statistics of cognitive attention data 


\begin{tabular}{|c|c|c|c|c|c|c|c|c|c|}
\hline & Variable & Mean & Variance & 1 & 2 & 3 & 4 & 5 & 6 \\
\hline 1 & Replies & 34.15 & 10319.806 & - & & & & & \\
\hline 2 & Clicks & 7930.10 & 639800000.00 & $0.926 * * *$ & - & & & & \\
\hline 3 & $\begin{array}{l}\text { Response } \\
\text { rate }\end{array}$ & 0.006595192964 & 0.000012466384 & $-0.120 * * *$ & $-0.203 * * *$ & - & & & \\
\hline 4 & Interaction & 2.57 & 8.595 & $0.530 * * *$ & $0.521 * * *$ & $-0.111 * * *$ & - & & \\
\hline 5 & $\begin{array}{l}\text { Reply time } \\
\text { (minute) }\end{array}$ & 16.89 & 30717.449 & -0.017 & -0.015 & -0.049 & -0.025 & - & \\
\hline 6 & $\begin{array}{l}\text { Duration } \\
\text { (minute) }\end{array}$ & 3504.59 & 76758144.626 & $0.354 * * *$ & $0.388 * * *$ & $-0.249 * * *$ & $0.289 * * *$ & 0.018 & - \\
\hline
\end{tabular}

Note: $N=1212$. The lower triangular matrix is correlation coefficients, $* p<0.05, * * p<0.01, * * * p<0.001$.

Table 5 . Correlation analysis between variables of cognitive attention

With the deepening of users' cognitive levels, attention resources inputs are also increasing. We can observe from the results of interactions' curve estimation in Table 6.The $F$ value of model 2 is 847.258 . The significance probability of $\mathrm{F}$ distribution is $p<0.001$. The $\Delta R^{2}$ is 0.411 and the significance level of regression coefficient is $p<0.001$. Those results indicate that the power function relationship between forum's interactions and duration is significant and the regression equation established is valid. The power function regression equation of forum's interaction is $Y=0.68 X^{0.642}$, in which $Y$ is forum's interaction and $X$ is duration. The fitted line of power function is shown as the dashed line in Figure 2. From the regression equation and the fitted curve graph, we can obtain that forum's interaction is increasing in the way of power function with increasing duration. The interaction gets rapider growth in the early stage of duration, and levels off gradually in the latter period, which indicates that users' cognitive attention is more likely to increase in the early stage of discussion.

\begin{tabular}{|c|r|r|}
\hline & \multicolumn{2}{|c|}{ Model 1 } \\
\hline Independent variable & Logarithmic & \multicolumn{2}{|c|}{ Power 2 } \\
\hline Duration & $0.479 * * *$ & $0.642 * * *$ \\
\hline$R^{2}$ & 0.229 & 0.412 \\
\hline$\Delta R^{2}$ & 0.229 & 0.411 \\
\hline Constant & $-0.530 * *$ & $0.680 * * *$ \\
\hline$F$ value & $360.166 * * *$ & $847.258 * * *$ \\
\hline
\end{tabular}

Note: $N=1212$. Significance levels: $* p<0.05, * * p<0.01, * * * p<0.001$.

Table 6. Curve estimation of interaction 


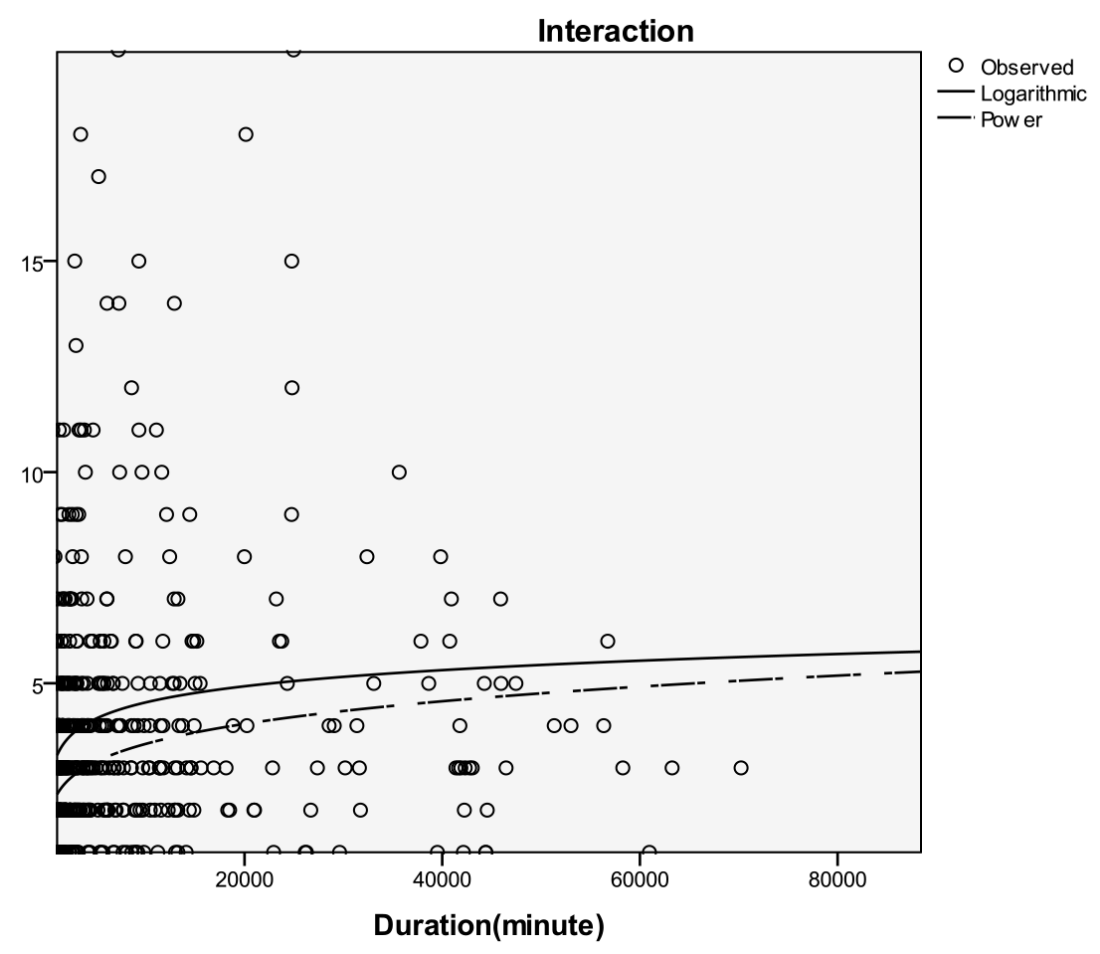

Figure 2. Fitted curve of interaction and duration

\subsection{The Interconnection Analysis between Visual Attention and Cognitive Attention}

Visual attention and cognitive attention can be connected by the behavior "click" in the Internet forums with higher viscosity. The regression results of forum's replies and clicks show that in Model 1 of Table 7, the $F$ value is 7306.480, the significance probability of $F$ distribution is $p<0.001$, and the $\Delta R^{2}$ is 0.858 . The standardized regression coefficient of clicks is 0.926 and the significance level is 0.001 . Those results indicate that the linear relationship between forum's replies and clicks is significant and the established regression equation is valid. The regression equation of forum's replies is $Y=0.04 X+4.649$, in which $Y$ is forum's replies and $X$ is clicks. In other words, with clicks increasing in forums, replies and comments will also increase (Figure 3).

\begin{tabular}{|c|r|r|}
\hline & \multicolumn{2}{|c|}{ Model 1 } \\
\hline Independent variable & $0.926 * * *$ & \\
\hline Clicks & & $0.354 * * *$ \\
\hline Duration & 0.858 & 0.125 \\
\hline$R^{2}$ & 0.858 & 0.124 \\
\hline$\Delta R^{2}$ & $7306.480 * * *$ & $172.968 * * *$ \\
\hline$F$ value & & \\
\hline
\end{tabular}

Note: $N=1212$. Significance levels: $* p<0.05, * * p<0.01, * * * p<0.001$.

Table 7. Linear regression analysis of forum's replies 


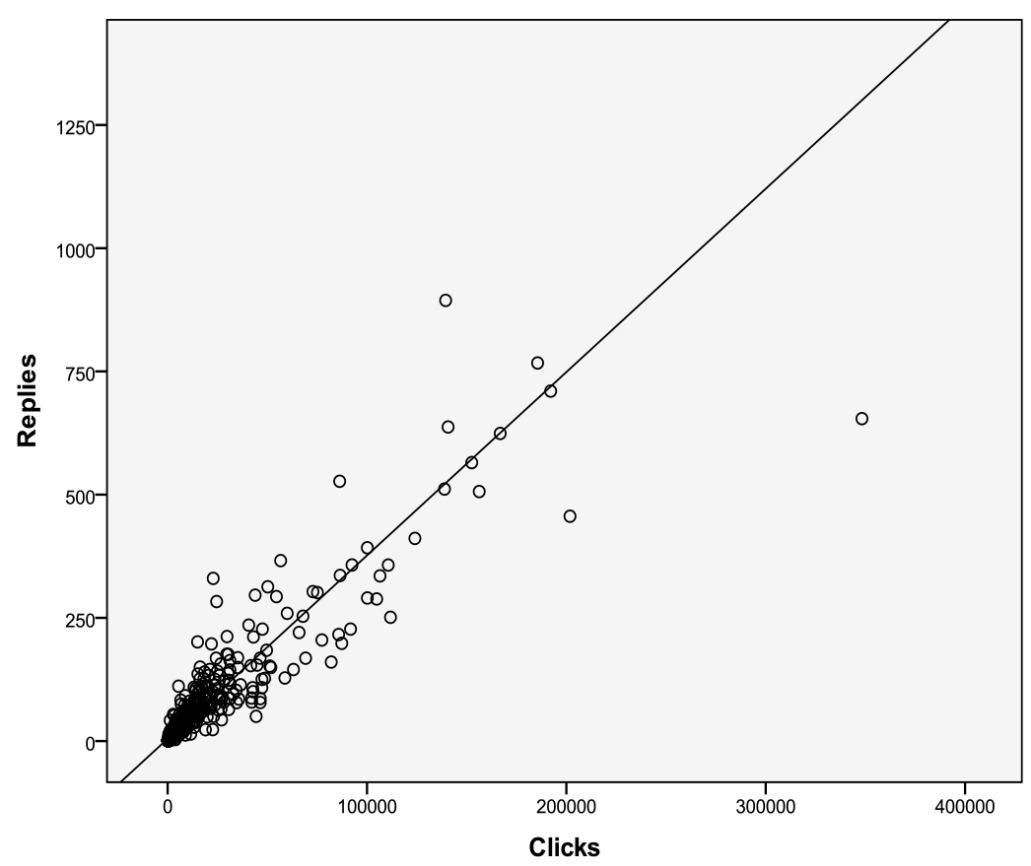

Figure 3. Linear fitted line of forum's replies

In addition, the regression results of forum's interactions and clicks are shown in Model 1 of Table 8 . The $\mathrm{F}$ value is 450.336 .The significance probability of $\mathrm{F}$ distribution is $p<0.001$ and the $\Delta R^{2}$ is 0.271 . The standardized regression coefficient of clicks is 0.521 and the significance level is $p<0.001$, similarly indicating that the linear relationship between forum's interactions and clicks is significant. That is if clicks increase, so will interactions do.

\begin{tabular}{|c|c|c|c|c|}
\hline & Model 1 & Model 2 & Model 3 & Model 4 \\
\hline \multicolumn{5}{|c|}{ Independent variable } \\
\hline Clicks & $0.521 * * *$ & & & \\
\hline Replies & & $0.530 * * *$ & & \\
\hline Response rate & & & $-0.111 * * *$ & \\
\hline Duration & & & & $0.289 * * *$ \\
\hline$R^{2}$ & 0.271 & 0.281 & 0.012 & 0.083 \\
\hline$\Delta R^{2}$ & 0.271 & 0.280 & 0.012 & 0.083 \\
\hline$F$ value & $450.336 * * *$ & $472.859 * * *$ & $15.094 * * *$ & $110.001 * * *$ \\
\hline
\end{tabular}

Note: $N=1212$. Significance levels: $* p<0.05, * * p<0.01, * * * p<0.001$.

Table 8. Linear regression analysis of forum's interactions

As can be seen from the above analysis, clicks connect users' visual attention and cognitive attention. Users click, think and then reply. Therefore, the significant correlation relationships 
between forum's replies and clicks, interactions and clicks, indicate that visual attention and cognitive attention contact each other and can be transformed. This transformation is from unconscious visual attention into conscious cognitive attention.

\section{Discussion}

Summarizing the results of relevant analysis, the distribution of attention resources in Internet forums has the following characteristics: (1) Internet forum's attention is mainly as visual attention in users' early involvement, and attention resources can be transformed. As the Internet forum has high viscosity, it can transform visual attention into cognitive attention after attracting users' visual focus, which enables users to participate deeply in discussions. (2) The distribution of visual attention is related to the peculiarity of website and users' experience. Brilliant visual appearance provided by Internet forums can better grab users' visual attention. But visual attention "fragmentation" caused by information "fragmentation" can't be ignored either. No matter from the point of network information services or customer experience, the expected improvement must deal with "fragmentation". (3) User group's cognitive attention about news events or hot issues in Internet forums has the characteristic of normal distribution. With the occurrence, activity and decline of event, cognitive attention also changes accordingly. The distribution of cognitive attention will be impacted by herding behavior and imitating behavior of groups in Internet forums. For example many of us are used to browsing popular posts. In addition, there are opinion leaders in Internet forums, whose opinions are likely to influence others' cognitive attention. (4) The distribution of cognitive attention has different levels. With the deepening of users' cognitive behaviors, attention resources input are also increasing. The more cognitive attention is put into the low cognitive level, the easier cognitive attention can develop further. The distribution levels of cognitive attention are also related to the duration of topics. If Duration of posts is longer, users' cognitive attention is also easier to develop deeply. (5) The cognitive attention behaviors' further development will lead to the complex distribution of cognitive attention. Cognitive attention input is prone to increase faster in the early stage of duration, which means that deep discussions and interactions are more likely to appear in the early stage.

Comparing prior similar studies about attention, there are some changes. Arvidson (2003) used psychological and neuropsychological literature on attention to discuss the nature of subjectivity in attention and attention research, and whether attention might be the same as consciousness. Van Dalen and Henkens (2005) got a group of 1,371 scientific articles published in 17 demography journals in the years 1990-1992 to trace which signals are important in gaining attention in science. Bruer (2010) traced prospectively the development of the cognitive neuroscience of attention, obtaining the relevant literature data to conduct an author co-citation analysis. Many attention researches focus on attention in science. Science, as an 
industry transforming attention into cognitive output, associates closely with attention (Franck, 2002). But now attention researches collect data not only from science literatures but also from social media data. Huberman, Romero and Wu (2009) used a massive data set from YouTube to analyze crowdsourcing, attention and productivity. Ko, Kwon, Kim, Lee and Choi (2014) used a simple mathematical model to analyze Twitter data for the Twitter dynamics and provided a good measure for the general public attention. Attention research has stepped into general's digital life. For users, finding out their attention features can help them get more accurate access to information needed to deal with the information explosion. For the operators of portals and Internet communities, results of attention research provide evidence to ameliorate their service and improve users' experience. For example, the website can optimize their interface with better visual appearance and more targeted service contents to attract users' visual attention at first. Because deep discussions and interactions are more likely to appear in the early stage, the website should find out the hot issues and provide instruction and inspection in time to contend for users' cognitive attention and increase more loyal users.

There are also some limitations about this study. At first, the factors affecting the distribution of attention resources in Internet forums are complex. So the measurement indicators are not comprehensive. Secondly, this paper didn't distinguish different types of Internet forums when we collected the relevant data. In the future work, how to obtain more comprehensive attention data is an improvement. Meanwhile, regarding different types of Internet forums, such as integrated forums, military forums, entertainment forums and so on, finding their own special traits and rules is another direction to target our efforts. Moreover, although this study has proposed that different forms of attention can transform into each other under certain conditions, how to find their transform rules or conditions is another important issue to be solved in future research.

\section{Acknowledgement}

This research is supported by the National Science Foundation of China (71373108).

\section{Reference}

Arvidson, P.S. (2003). A lexicon of attention: From cognitive science to phenomenology. Phenomenology and the Cognitive Sciences, 2, 99-132. http://dx.doi.org/10.1023/A:1024895827774

Baluja, S., \& Pomerleau, D.A. (1997). Expectation-based selective attention for visual monitoring and control of a robot vehicle. Robotics and Autonomous Systems, 22(3-4), 329-344. http://dx.doi.org/10.1016/S0921-8890(97)00046-8 
Bruer, J.T. (2010). Can we talk? How the cognitive neuroscience of attention emerged from neurobiology and psychology, 1980-2005. Scientometrics, 83(3), 751-764. http://dx.doi.org/10.1007/s11192-009-0128-5

Courbet, D., Fourquet-Courbet, M.P., Kazan, R., \& Intartaglia, J. (2014). The Long-Term Effects of E-Advertising: The Influence of Internet Pop-ups Viewed at a Low Level of Attention in Implicit Memory. Journal of Computer-mediated Communication, 19(2), 274-293. http://dx.doi.org/10.1111/jcc4.12035

Davenport, T.H., \& Beck, J.C. (2001). The attention economy. Boston, MA: Harvard Business School Press.

Dahlberg, L. (2001). The Internet and democratic discourse: Exploring the prospects of online deliberative forums extending the public sphere. Information, Communication \& Society, 4(4), 615-633. http://dx.doi.org/10.1080/13691180110097030

Franck, G. (2002). The scientific economy of attention: A novel approach to the collective rationality of science. Scientometrics, 55(1), 3-26. http://dx.doi.org/10.1023/A:1016059402618

Hong, W., Thong, J.Y.L., \& Tam, K.Y. (2004). Does animation attract online users' attention? The effects of flash on information search performance and perceptions. Information Systems Research, 15(1), 60-86. http://dx.doi.org/10.1287/isre.1040.0017

Huang, Y.X., \& Luo, Y.J. (2007). Attention shortage resistance of negative stimuli in an implicit emotional task. Neuroscience Letters, 412, 134-138. http://dx.doi.org/10.1016/j.neulet.2006.10.061

Huberman, B.A., Romero, D.M., \& Wu, F. (2009). Crowdsourcing, attention and productivity. Journal of Information Science, 35(6), 758-765. http://dx.doi.org/10.1177/0165551509346786

Koch, C., \& Ullman, S. (1987). Shifts in Selective Visual Attention: Towards the Underlying Neural Circuitry. Matters of Intelligence Synthese Library, 188, 115-141. http://dx.doi.org/10.1007/978-94-009-3833-5_5

Kortelainen, T., \& Katvala, M. (2012). Everything is plentiful-Except attention. Attention data of scientific journals on social web tools. Journal of Informetrics, 6(4), 661-668. http://dx.doi.org/10.1016/j.joi.2012.06.004

Ko, J., Kwon, H.W., Kim, H.S., Lee, K., \& Choi, M.Y. (2014). Model for Twitter dynamics: Public attention and time series of tweeting. Physica A-statistical Mechanics and its Applications, 404, 142-149. http://dx.doi.org/10.1016/j.physa.2014.02.034

Morzy, M. (2009). On Mining and Social Role Discovery in Internet Forums. International Workshop on Social Informatics, Proceedings. 74-79. http://dx.doi.org/10.1109/SocInfo.2009.22 
Netto, M., Assunçao, M.D., \& Bianchi, S. (2013). Leveraging attention scarcity to improve the overall user experience of cloud services. In Network and Service Management (CNSM), 9th International Conference on. IEEE. 84-91. http://dx.doi.org/10.1109/CNSM.2013.6727813

Potter, R.E., \& Balthazard, P. (2004). The role of individual memory and attention processes during electronic brainstorming. Mis Quarterly, 28(4), 621-643.

Schneider, U. (2002). The Knowledge-Attention-Gap: Do We Underestimate the Problem of Information Overload in Knowledge Management? Journal of Universal Computer Science, $8(5), 482-490$.

Simon, H.A. (1971) Designing organizations for an information-rich world. In Greenberger, M. (Ed.). Computers, communications, and the public interest. Baltimore, MD: The John Hopkins Press.

Van Dalen, H.P., \& Henkens, K. (2005). Signals in science - On the importance of signaling in gaining attention in science. Scientometrics, 64(2), 209-233. http://dx.doi.org/10.1007/s11192-0050248-5

Wikipedia (2015). Introduction of Bounce Rate [Online community]. Last access: July 2015. https://en.wikipedia.org/wiki/Bounce_rate

Wolfe, J.M., Friedmanhill, S.R., \& Bilsky, A.B. (1994). Parallel-processing of Part-whole Information in Visual-search Tasks. Perception \& Psychophysics, 55(5), 537-555. http://dx.doi.org/10.3758/BF03205311

Wu, W. (2011). What is conscious attention? Philosophy and Phenomenological Research, 82(1), 93-120. http://dx.doi.org/10.1111/j.1933-1592.2010.00457.x

Zhang, L. (2002). Attention economics. Zhejiang: Zhejiang University Press.

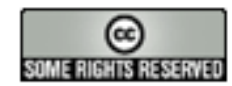

Article's contents are provided on an Attribution-Non Commercial 3.0 Creative commons license. Readers are allowed to copy, distribute and communicate article's contents, provided the author's and Journal of Industrial Engineering and Management's names are included. It must not be used for commercial purposes. To see the complete license contents, please visit http://creativecommons.org/licenses/by-nc/3.0/. 